\title{
A longitudinal analysis of the spatial spread of police-investigated physical child abuse
}

\author{
Andrew Grogan-Kaylor ${ }^{\mathrm{a}}$, Julie Ma ${ }^{\mathrm{b}}$, Shawna J. Lee ${ }^{\mathrm{a}}$, Sacha Klein ${ }^{\mathrm{c}, *}$ \\ ${ }^{a}$ University of Michigan, School of Social Work, United States \\ ${ }^{\mathrm{b}}$ University of Michigan Flint, Department of Social Work, United States \\ ${ }^{\mathrm{c}}$ Michigan State University, School of Social Work, United States
}

\section{A R T I C L E I N F O}

\section{Keywords:}

Police-investigated physical child abuse

Neighborhoods

Child maltreatment

Longitudinal spatial model

\begin{abstract}
A B S T R A C T
Background: Research has shown that problematic behaviors, such as violence and drug use, may spread through shared physical space and social norms, lending rise to the notion of contagion theories of human behavior.

Objective: This study examines whether physical child abuse spreads across time and space in a pattern reflective of a contagion model.

Participants and Setting: This study uses 15 years of data from a large U.S. city police department. Data points are geo-located police-investigated physical child abuse incidents that occurred from 2001 to 2015.

Methods: Police department data are combined with U.S. Census estimates of the number of child residents in each of the Census Tract comprising the study site to derive annual rates of policeinvestigated physical child abuse cases per 1000 children residing in each Census tract. A panel data spatial regression model is used to analyze the association between this dependent variable, the rate of police-investigated physical child abuse cases in surrounding Census tracts, and time. The analysis statistically controls for multiple covariates commonly associated with Census tractlevel estimates of child maltreatment, specifically household median income, residential instability, racial composition, population density, and the concentration of child residents. Results: The rate of physical child abuse in a Census tract is positively associated with the rate of physical child abuse in the surrounding Census tracts, net of the covariates and the effect of time $(\beta=0.461, p<.001)$.

Conclusion: This finding provides preliminary evidence that physical child abuse, like some other problematic human behaviors, may spread spatially.
\end{abstract}

\section{Introduction}

Child maltreatment is a major public health crisis in the U.S. In 2017, state Child Protection Services (CPS) agencies responded to maltreatment allegations regarding approximately 3.5 million children. More than $17 \%$ were found to be substantiated victims of maltreatment, and $17 \%$ of children with substantiated cases of maltreatment experienced physical child abuse (U.S. Department of Health and Human Services; USDHHS, 2017). Research suggests that the annual statistics grossly underestimate the likelihood that any individual child will experience maltreatment. Using synthetic cohort analysis of a national data source, researchers estimated

\footnotetext{
*Corresponding author at: School of Social Work, Michigan State University, 246 Baker Hall, 655 Auditorium Road, East Lansing MI, 48824, United States.

E-mail address: kleinsa@msu.edu (S. Klein).
} 
that $12.5 \%$ of all U.S. children would experience a confirmed case of maltreatment by 18 years of age (Wildeman et al., 2014). The public health implications of child maltreatment are clear. The Adverse Childhood Experiences Study (ACES) shows that adults who were maltreated as children are more likely than non-maltreated adults to perpetrate or be victimized by intimate partner violence (Whitfield, Anda, Dube, \& Felitti, 2003), to be obese (Williamson, Thompson, Anda, Dietz, \& Felitti, 2002), and to have lower levels of health-related quality of life (Corso, Edwards, Fang, \& Mercy, 2008). In comparison to other industrialized countries, the U.S. stands out as having an exceptionally high rate of child death due to maltreatment-which is most often the result of neglect and physical child abuse-nearly double the rate of the next highest country, New Zealand (United Nation's Children's Fund; UNICEF, 2003).

A long tradition of research in the field of child maltreatment has examined how ecological factors such as neighborhood contexts contribute to the etiology of child maltreatment. Prior studies have identified concentrated economic disadvantage, crime, and social disorganization as neighborhood-level risks of child maltreatment (Coulton, Crampton, Irwin, Spilsbury, \& Korbin, 2007; Morris et al., 2018). Yet, the question of whether child maltreatment is contagious such that child abuse incidents in a neighborhood may influence abusive acts towards children in nearby neighborhoods has not been examined. In this study, we propose that spatial spread processes (Fagan, Wilkinson, \& Davies, 2007) may explain some of the variations in neighborhood physical child abuse (PCA) rates over time. To examine the hypothesis that spatial spread (i.e., the tendency of human behaviors to diffuse across time and space, sometimes described as a "contagion" effect) is a unique factor that contributes to child maltreatment rates, we conduct a longitudinal spatial analysis of a highly novel data source in the field of child maltreatment-publicly available police-investigated child maltreatment data from a large city in the Midwestern United States. This study examines neighborhood rates of police-investigated PCA over 15 years to determine whether there is evidence for "spatial spread" or diffusion of police-investigated PCA, from adjoining Census tracts to a Census tract, over time.

\subsection{Ecological models of the etiology of maltreatment}

Most studies of the etiology of maltreatment have focused on the microanalysis of individual (e.g., parental substance use) and family-level (e.g., domestic violence) characteristics that drive parents' abusive and neglectful behavior. However, the ecological or "person-in-environment" framework suggests that risk for child maltreatment is complex, and explained by proximal factors (e.g., "microsystems") that may affect dynamics of the parent-child relationship and household characteristics, as well as by factors in the broader environmental contexts in which families live (e.g., "exosystems" and "macrosystems"; Belsky, 1993).

Indeed, studies employing an ecological framework have shown that child maltreatment rates are higher in neighborhoods, typically operationalized as Census tracts, Census block groups, or zip codes, with higher rates of poverty (Drake \& Pandey, 1996; Freisthler, 2004), unemployment (Merritt, 2009; Molnar, Buka, Brennan, Holton, \& Earls, 2003), residential instability, and housing stress (e.g., large concentrations of vacant homes) (Klein \& Merritt, 2014), or factor scores or scales inclusive of some or all of these variables (Coulton et al., 2007; Coulton, Korbin, \& Su, 1999). There is some evidence that child maltreatment rates may be higher in neighborhoods that are sparsely populated (Freisthler, 2004; Freisthler, Midinak, \& Gruenewald, 2004), have high levels of "child care burden" or a lack of informal resources (e.g., adult residents) for child supervision (Coulton, Korbin, Su, \& Chow, 1995, 1999; Klein \& Merritt, 2014; Klein, 2011; Merritt, 2009), and are racially diverse or have high concentrations of some minority groups (Freisthler, 2013; Klein, 2011; Klein \& Merritt, 2014).

\subsection{Spatial co-location and spread of violence}

We focus on the notion of geographical proximity of neighborhoods (in this study, operationalized by Census tracts) and spatial spread or diffusion of physical child abuse as a factor that may explain fluctuations in police-investigated PCA over time. The concept of spatial spread states that (a) analogous to the spread of infectious diseases, social behaviors are also vulnerable to spread (or diffusion) in neighborhoods-a phenomena that may be pronounced in urban areas, where there are densely packed social relationships and networks, and (b) social behaviors and beliefs can spread through interactions by people in proximal social structures (Fagan et al., 2007). In this study, we focus on demonstrating statistical evidence for the first part of this concept, (a) diffusion across neighborhoods, specifically, showing that rates of police-investigated PCA in adjoining neighborhoods (Census tracts) are associated with the spread of police-investigated PCA to a neighborhood (Census tract) over time.

As outlined by Fagan et al. (2007), spatial spread (or contagion) of behavior may occur via direct exposure to violence and aggression, and such exposure thus normalizes the occurrence of those behaviors (Bond \& Bushman, 2017). In other words, the occurrence of the behavior "creates an environment where future occurrences are more likely to occur" (Degarmo, 2011, p. 589). Over time, increased exposure elevates the likelihood that the behavior will occur and contributes to the "spread" of the behavior to adjoining geographical locations. Fagan et al. (2007) document trends suggesting that youth homicide rates can be linked through spatial spread and contagion processes.

In addition to youth violence (Fagan et al., 2007), spatial co-location and geographical spread processes have been observed to occur in several other domains of human behavior. One study examined the spatial co-location of crime in a Canadian city and found that certain forms of criminal activity tended to co-occur (Andresen \& Jenion, 2008). Another study used police data to examine the spatio-temporal movement of different forms of homicide in an urban area, and their longitudinal analysis showed both clustering (spatial co-location) of homicides as well as spatial spread, which they call diffusion, of gang motivated homicide over 10 years (Zeoli, Grady, Pizarro, \& Melde, 2015). Gruenewald et al. (2013) demonstrated how methamphetamine use showed signs of growth and spatial spread in low-income areas, with evidence that laws to reduce methamphetamine use were effective at reducing 
contagion in some areas. This study also shows that as the behavior spreads, there may be a nonlinear growth over time (Gruenewald et al., 2013).

Similar to these prior studies, in the current study, the co-location of police-investigated PCA is operationalized as a function of shared physical space (e.g., neighborhoods, operationalized as Census tracts). Several studies have shown that child maltreatment tends to be spatially correlated. For example, neighborhoods with high rates of maltreatment tend to cluster together geographically (Paulsen, 2004), a phenomenon known as spatial dependence. Lery (2009) used spatial data analysis and showed that foster care entries in one neighborhood were spatially correlated with foster care entries in adjoining neighborhoods.

One explanation for spatial dependence is measurement error, or the understanding that neighborhood boundaries, especially when defined by administrative units like the post office or U.S. Census Bureau, often artificially split cohesive communities (Coulton, Jennings, \& Chan, 2013; Sampson, Morenoff, \& Gannon-Rowley, 2002). Thus, two adjoining neighborhoods may appear to have similar maltreatment rates, at least partially because the two neighborhoods function and perceive themselves as a single community. A similar problem occurs when administrative units artificially combine functionally distinct communities. However, there is an alternative explanation for spatial dependence. Distinct but adjoining Census tracts may have similar rates of child abuse because, levels of informal social control, which is associated with lower levels of PCA (Emery, Trung, \& Wu, 2015), may be spatially correlated across neighborhoods. To test this alternative explanation for spatial dependence, however, longitudinal data is needed so that the combined effect of geographic proximity and the passage of time can be explored (StataCorp, 2017a). The central hypothesis of the current study is that changes in police-investigated PCA rates within a Census tract will be partially explained by the spatial spread from adjoining Census tracts in a large U.S. city over 15 years. Although there is research examining spatial processes in interpersonal violence (Almgren, 2005), few studies in child welfare research to date have employed spatial models for longitudinal data while, as we detail below, providing separate estimates of the effect of socioeconomic characteristics of neighborhoods, spatial spread, and the continuity of Census tracts over time.

To examine this hypothesis, we use a novel source of publicly available data that comes from call reports of police-investigated physical child abuse from the police department of a large city in the United States. Cross, Finkelhor, and Ormrod, (2005) note several ways in which child protection services and law enforcement function differently in addressing child maltreatment. Child Protective Services (CPS) is the system that intervenes to determine whether an allegation of maltreatment is substantiated, and, following allegations, determines the nature of services, if any, to be delivered to the family. Law enforcement becomes involved when "there is suspicion that the reported child maltreatment involved a criminally prosecutable act" (Cross et al., 2005, p. 3). Also, as a safety precaution, police may be called when CPS mandates removal of a child from the home (Cross et al., 2005). The standard for police involvement is almost always much higher when compared to CPS involvement because CPS determines whether to investigate allegations of maltreatment independent from consideration of whether the abuse constitutes a criminally prosecutable act. Furthermore, child removal is warranted only when a child is at imminent risk of physical harm, further demonstrating that police are usually involved in only the most severe cases of maltreatment encountered by formal surveillance systems (Cross et al., 2005).

Although police data is not widely used in child welfare research, numerous other fields have used police and crime data to examine spatial spread and contagion hypotheses. Indeed, such administrative data is often publicly available from police departments. Building on social disorganization theory, Andresen (2006) used data of geo-located police service calls made to the Vancouver police department, along with Canadian Census data, to conduct a spatial analysis of crime rates and Census tract characteristics associated with those crime rates. Similarly, using crime data from police departments, other studies have used spatial analyses to examine how characteristics of the physical environment in neighborhoods are linked to negative behaviors such as felonious battery (Caplan, Marotta, Piza, \& Kennedy, 2014), alcohol-related IPV (Cunradi, Mair, Ponicki, \& Remer, 2011), and homicide and gang violence (Zeoli et al., 2015).

Another component of this current study is the use of Census tracts to approximate neighborhoods, which are commonly used units of measurement in neighborhood studies, in part because Census tract data is publicly available. While this approach has limitations, for example, Census tracts are not always aligned with neighborhood boundaries, the use of Census tracts in the analysis of neighborhood contexts is commonplace. For example, Lery (2009) used Census tracts and Census block groups in California to examine foster care entry patterns and found that the strength of associations linking neighborhood economic disadvantage to foster care entry changed little among spatial scales. Numerous other studies that have employed a variety of spatial analysis techniques have used aggregated Census tract data (Andresen, 2006; Gorman, Zhu, \& Horel, 2005; Zeoli et al., 2015).

\section{Methods}

\subsection{Research design}

To examine our research question regarding the contagion of physical child abuse across across time and space, we employed a longitudinal repeated measures research design based on 15 years (2001-2015) of police-investigated child physical abuse cases. Every row of the data set represented a particular year for a particular Census tract, which is the unit of analysis for our study. Thus, each Census tract had 15 rows of data, one for every year. Census tracts are often used as proxies for neighborhoods in child maltreatment research (Coulton et al., 2007; Freisthler, Lery, Gruenewald, \& Chow, 2006) because they are large enough to capture meaningful variations in a low base rate phenomenon like child abuse, but also small enough to capture local effects that would be obfuscated by larger units of analyses, such as zip codes (Klein \& Merritt, 2014). 


\subsection{Data sources}

\subsubsection{Police data}

The police-investigated PCA cases came from publicly available data files from the police department of a large U.S. city. Data for January 1, 2001, to December 31, 2015, were obtained from the city website and were downloaded into an Excel spreadsheet, which was then subsequently read into Stata statistical software. The Excel spreadsheet contained 11,177 incidents of police-investigated child abuse. Each record in the data contained a geographic identifier denoting the location of the incident.

To examine the validity of our measure of police-investigated PCA, we examined CPS rates of substantiated cases of physical maltreatment in the state that the city in question is located. We would expect to see a comparable but lower rate of policeinvestigated PCA when compared to CPS-substantiated PCA. The state-level rate of CPS-substantiated PCA in 2010 was 1.8 cases per 1000 children. The rate of police-investigated PCA in the current study was 1.1 per 1000 children. Thus, although we do not know the severity or nature of the PCA for the data points in this study, we have reason to believe that our source of data reflects a subsection of the most serious forms of PCA that came into contact with surveillance systems.

\subsubsection{Geographic data on census tracts}

Geographic "shapefiles" of city Census tracts were obtained from simplymap.com, a proprietary vendor of geographic data. "Shapefiles" contained information on demographic, social, and economic characteristics of Census tracts, from the 2000 and 2010 Censuses described in more detail below.

\subsection{Measures}

\subsubsection{Year}

The calendar year during which police responded to PCA was coded in the Police data.

\subsubsection{Police-investigated PCA}

The dependent variable is the number of PCA cases in the Census tract recorded by police per 1000 child residents in a given year, based on official crime records that were filed as valid child abuse incidents by the police department of the city in question. This reporting of child abuse is limited to physical maltreatment of children by caregivers or family members in the child's home and excludes sexual abuse, abandonment, or neglect, which are tracked separately.

\subsubsection{Covariates}

Based on prior research (Freisthler et al., 2006; Sampson, Raudenbush, \& Earls, 1997), covariates for neighborhood characteristics were derived from Census data. For data to match the police-investigated PCA data for years 2001-2009, covariates were derived from the 2000 decennial Census; for police-investigated PCA data from years 2010-2015, covariates were derived from the 2010 decennial Census.

2.3.3.1. Household median income. Household median income was entered into the regression model in $\$ 10,000$ increments as an indicator of socioeconomic advantage/disadvantage.

2.3.3.2. Child care burden. The ratio of children to adults in a given Census tract was used as an indicator of child care burden. This variable was derived by dividing the number of residents of the tract who were 14 or younger by the number of adult residents who were 20 through 64 years.

2.3.3.3. Percent population who were Black. The percentage of the population in a given Census tract who identified as Black relative to other races and ethnic groups represented racial composition in a given Census tract.

2.3.3.4. Residential instability. This variable was derived from the median year that residents of a given tract had moved into their current residence to indicate residential stability, with higher numbers reflecting more residential instability or turnover.

2.3.3.5. Population density. The number of residents per square mile was used as an indicator of population density in a given Census tract.

\subsection{Analysis strategy}

\subsubsection{Spatial join}

Our first data management task was to use a "spatial join" to match the geographic location of each incident of police-investigated PCA to the Census tract in which it occurred. As detailed in Fig. 1, each observation of PCA, represented by a dot, was matched to the appropriate Census tract within which the abuse incident occurred, represented by a square. The spatial join was accomplished using ArcGIS 10.3.1. Counts of police-investigated PCA incidents were then aggregated across each tract for each year, resulting in a data file in which each row of data represented a particular Census tract in a particular year. 


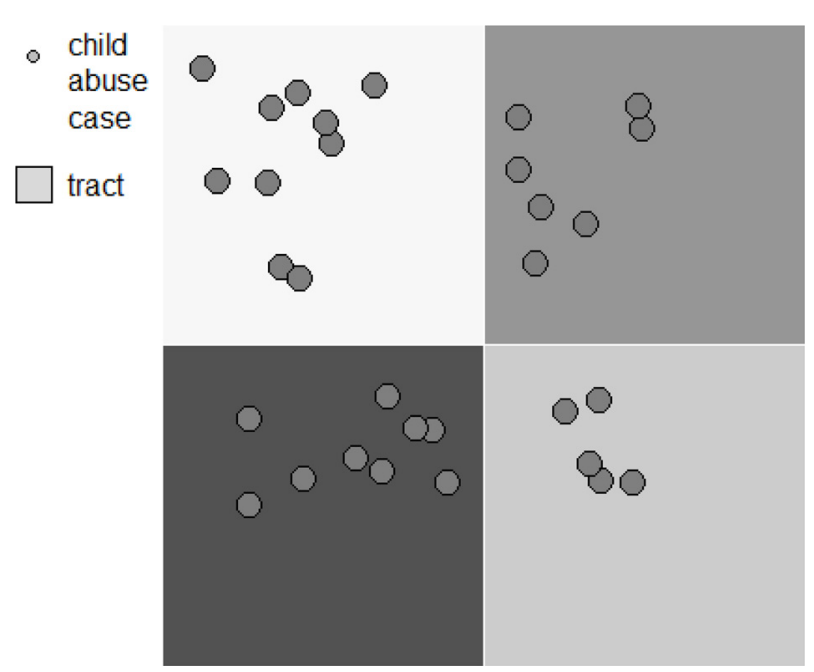

Fig. 1. Simulated spatial join of points to Census tracts.

Figure note: Each observation of PCA, represented by a dot, was matched to the appropriate Census tract within which the abuse event occurred, represented by a square. Counts of incidents of police-investigated PCA were then aggregated across each tract for each year, resulting in a data file in which each row of data represented a particular Census tract in a particular year.

\subsubsection{Spatial regression for panel data}

Our statistical model estimated the factors associated with the rate of child abuse in Census tracts over time. As noted, in our data set, every observation, or row of data, represented a particular year for a particular Census tract. Thus, every Census tract had multiple rows of data. These multiple rows per Census tract were likely to be correlated. We also recognized that there was likely to be spatial autocorrelation across tracts that were geographically close to each other. Failure to account for the correlation of repeated measures data, as well as spatial autocorrelation, and spatial lag of the dependent variable, could lead to misestimation of standard errors, as well as biased coefficients.

In some cases, a misestimation of standard errors could lead to attributions of statistical significance where this was not appropriate. In order to account for the repeated measures and spatially correlated nature of our data, we employed a spatial regression model appropriate for panel data (StataCorp, 2017a) to estimate the growth trajectory of the rate of police-investigated PCA across Census tracts while accounting for both the temporal and spatial correlations. All statistical models were estimated using Stata 15. This model accounted for both spatial correlations as well as the correlation of observations over time arising from the structure of the repeated measures of this data (StataCorp, 2017b).

We estimated a full spatial regression model for panel data with the relevant covariates. Our statistical model was of the following form:

$$
\begin{aligned}
& y_{i t}=\beta_{0}+\beta_{1} \text { year }+\beta_{2} \text { median income }+\beta_{3} \text { percentage children }+\beta_{4} \text { percentage black }+\beta_{5} \text { median year moved in }+\beta_{6} \\
& \text { population density }+\beta_{7} \mathrm{~W} y_{i t}+u_{O i}+W v_{i t}+e_{i t}
\end{aligned}
$$

Here, $\mathrm{y}_{i t}$ measured the cases of police-investigated PCA for Census tract $i$ at time $t . \beta_{0}$ was the overall intercept for the time trajectory of the outcome. The other $\beta$ 's were associated with the independent variables. Notably, $\beta_{7}$ was the regression coefficient for a spatial lag of our dependent variable, rates of PCA, weighted by the spatial weighting matrix W. The $\mathrm{u}_{0 \mathrm{i}}$ was an "individual specific" error term for Census tract $i$ across the time periods; $v_{i t}$ was a spatially autocorrelated error term, also weighted by the spatial weighting matrix $\mathrm{W} ; \mathrm{e}_{\mathrm{it}}$ was an error term for Census tract $i$ at time $t$.

The weighting matrix W identified whether each polygon (Census tract) in the dataset was contiguous ("1") or not contiguous ("0") to every other Census tract in the data set. We defined contiguity by so-called "queen contiguities" (Lai \& So, 2009) in which Census tracts could be touching along a boundary, or at a single point. A heuristic illustration is provided in Fig. 2 . In this figure, the central square is the Census tract in question. The middle ring of squares represents those polygons determined to be contiguous to the central square while the outer ring of Census tract polygons is not contiguous to the central square. For each polygon in the data set, a list of contiguous or touching polygons is generated. The end product of this process is a list of all Census tracts in the shapefile with the polygons that touch or are contiguous to each tract.

\section{Results}

\subsection{Descriptive statistics}

As seen in Table 1, the average rate of police-investigated PCA was 1.10 per 1000 child residents per Census tract per year. The minimum rate of police-investigated PCA was 0 children per 1000 child residents, while the maximum rate was 23.81 children per 


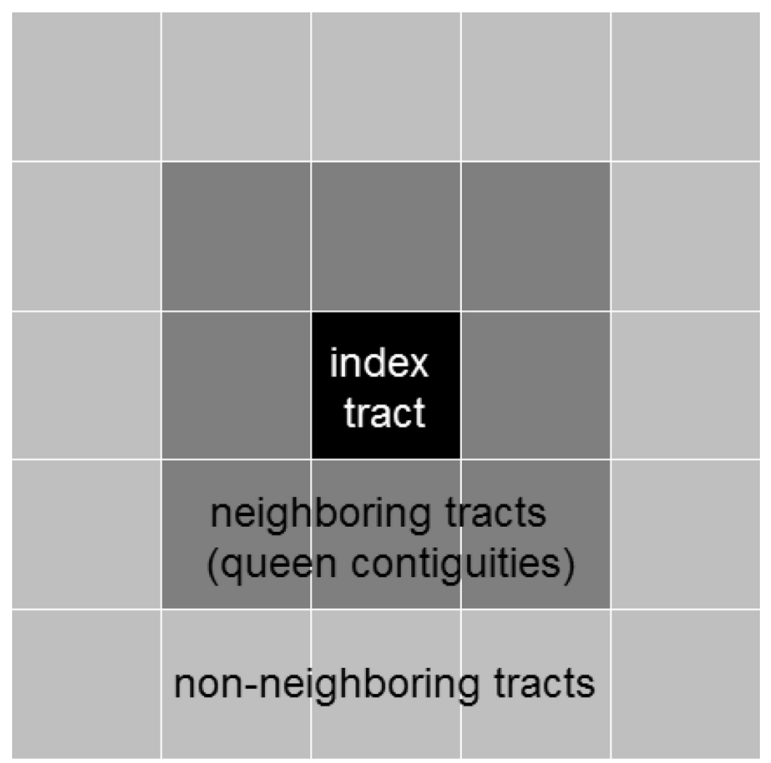

Fig. 2. Heuristic diagram of spatial matrix.

Figure note: In this figure, the central square is the Census tract in question. The middle ring of squares represents those polygons determined to be contiguous to the central square while the outer ring of Census tract polygons is not contiguous to the central square. For each polygon in the data set, a list of contiguous or touching polygons is generated. The end product of this process is a list of all Census tracts in the shapefile with the polygons that touch or are contiguous to each tract.

Table 1

Descriptive Statistics.

\begin{tabular}{|c|c|c|c|c|}
\hline Variable & Mean & Standard Deviation & Minimum & Maximum \\
\hline Number of Physical Child Abuse Cases / 1000 Children & 1.10 & 1.72 & 0.000 & 23.81 \\
\hline Year & 2008 & 4.32 & 2001 & 2015 \\
\hline Household Median Income & $\$ 43,422$ & $\$ 20,510$ & $\$ 9388$ & $\$ 171,176$ \\
\hline Percent Population Who Are Children & 25.59 & 9.18 & 2.12 & 57.26 \\
\hline Percent Population Black & 40.66 & 42.23 & 0.03 & 99.34 \\
\hline Median Year Moved In & 1995 & 5.65 & 1972 & 2004 \\
\hline Population Density & 18,866 & 12,396 & 469 & 99,719 \\
\hline
\end{tabular}

1000 child residents. The average median household income was just over $\$ 43,000$ (annually), but this variable ranged considerably across tracts (\$9388-\$171,176). On average, just over a quarter (25.59\%) of the individuals in each Census tract were children, and a substantial minority of individuals in each Census tract identified as Black (40.66 \%). The average of the median year in which residents moved into their residence was 1995. The average Census tract had approximately 19,000 persons per square mile, which is indicative of the urban nature of the study area. Estimation of an intra-class correlation coefficient suggested that approximately 13.7 $\%$ of the variation in our outcome could be explained by differences between Census tracts that were consistent over time, thus warranting the use of a spatial regression model for panel data.

\subsection{Results from spatial regression model for panel data}

Results ( $\beta$ coefficients) from the full spatial model with covariates shown in Table 2 may be interpreted in terms of absolute changes in the dependent variable; here the number of cases of police-investigated PCA per 1000 children living within a given Census tract.

\subsubsection{Results for the main study hypothesis}

Consistent with our hypothesis regarding the geo-temporal spread or "contagion" of child abuse, an increase in the rate of policeinvestigated PCA in neighboring Census tracts was associated with increases in the rate of police-investigated PCA in a tract. Every additional case of PCA per 1000 children in neighboring Census tracts was associated with .46 more cases of PCA per 1000 children in the focal tract.

\subsubsection{Results for study covariates}

As seen in Table 2, every $\$ 10,000$ increase in median household income was associated with an approximately $8 \%$ reduction 
Table 2

Results from Spatial Regression Models for Panel Data Predicting the Rate of Physical Child Abuse in Census Tracts.

\begin{tabular}{lll}
\hline Variable & Coefficient & Standard Error \\
\hline Year & -0.007 & 0.004 \\
Household Median Income \$10 K Increments & -0.076 & 0.019 \\
Percent of Population Who Are Children & -0.024 & 0.004 \\
Percent Population Black & 1.244 & 0.086 \\
Median Year Moved In & 0.014 & 0.006 \\
Population Density & -0.000 & 0.000 \\
Constant & -1.795 & \\
Spatial Weights & Coefficient & \\
Spatial Lag of Child Abuse & 0.461 & \\
Spatially Autoregressive Errors & -0.337 & 0.040 \\
\end{tabular}

Note: ${ }^{*} p<0.05 ; * * p<0.01 ; * * * p<0.001$.

Pseudo $R^{2}=.09$.

$(-.076$ child per 1000 children) in police-investigated PCA $(p<.001)$. Every $1 \%$ increase in child care burden, or the percentage of population of a Census tract who were children, resulted in a very small decrease in police-investigated PCA $(p<.001)$. Over time, every $1 \%$ increase in the population identifying as Black was associated with a 1.2 increase in police-investigated PCA cases $(p<.001)$.

The median year in which residents of a particular Census tract moved into their dwellings was also associated with policeinvestigated PCA incidents. As the median year became more recent, indicating higher levels of residential turnover within the tract, child abuse cases also went up $(p<.05)$. The calendar year and population density were not significantly associated with cases of police-investigated PCA.

\section{Discussion}

In this study, we apply the framework of contagion theory to examine the geo-temporal spread of PCA over 15 years in a large U.S. city. We use a novel data source: official police data. Results showed that the average rate of police-investigated PCA was 1.1 per 1000 child residents per Census tract per year. Results regarding the association of neighborhood-level covariates to rates of policeinvestigated PCA were largely in the expected directions and consistent with prior research. This is important because it suggests that our measure of police-investigated PCA is a valid measure of maltreatment risk, albeit one that likely captures the most serious cases of PCA (as discussed above; see Cross et al., 2005). In the current study, rates of police-investigated PCA were higher in Census tracts with lower median household incomes. Rates of police-investigated PCA were also higher in neighborhoods with a higher percentage of Black residents. These findings echo studies that found that CPS-investigated child maltreatment is greater in neighborhoods with higher concentrations of Black residents, which are also neighborhoods that tend to have higher rates of socio-economic disadvantage (Coulton et al., 1995, 1999; Freisthler, 2013; Freisthler, Bruce, \& Needell, 2007; Freisthler, Kepple, \& Holmes, 2012; Klein, 2011; Klein \& Merritt, 2014).

The results of this study also supported our hypotheses regarding the potential for contagion theory to explain some of the variations in neighborhood-level PCA. Specifically, we found that increases in police-investigated PCA in neighboring Census tracts are associated with higher levels of police-investigated PCA in a Census tract. Even when controlling for the socio-economic characteristics of neighborhoods, there is evidence that higher rates of PCA in surrounding neighborhoods are associated with higher rates of PCA in a particular neighborhood.

\subsection{Potential explanatory mechanisms}

One could interpret the finding that the rate of police-investigated PCA in surrounding neighborhoods positively predicts rates of police-investigated PCA within a neighborhood as evidence that child maltreatment may be more than just an individual choice by a parent; it may also be the result of group processes or shared social norms that contribute to conditions under which negative (or positive) behaviors occur. In other words, the strength of the network ties within a neighborhood may increase the risk for the behavior to spread among others in the neighborhood. Although we do not examine social network mechanisms in the current study, one possible interpretation is that PCA may be transmitted through social relationships, at least among neighbors. Such processes have been examined concerning other forms of violence. As explained by Fagan et al. (2007), social contagion of behaviors may occur via several mechanisms, including direct exposure to forms of violence and aggression, which is a strong predictor of the perpetration of violence (Bingenheimer, Brennan, \& Earls, 2005). In this line of thinking, behaviors spread through social networks to normalize their occurrence (Bond \& Bushman, 2017; Fagan et al., 2007). Over time, increased exposure or spread of behaviors increases the likelihood that the behavior will occur. Some prior studies document spatial spread or diffusion of behaviors that suggest contagion processes (Fagan et al., 2007; Gruenewald et al., 2013; Zeoli et al., 2015). Such processes have been documented concerning obesity (Christakis \& Fowler, 2007) and youth substance use (Ennett, Flewelling, Lindrooth, \& Norton, 1997; Rowe, Chassin, Presson, Edwards, \& Sherman, 1992). While much physical abuse of children occurs in private homes where neighbors do not directly observe it, we suggest that neighbors are often exposed to PCA through a combination of direct observation of child abuse when it occurs in 
public spaces (e.g., at a local grocery store or park), behaviors related to child abuse (e.g., spanking children, parent-to-child verbal aggression, and other forms of harsh parenting in public places) and indirect exposure. As with other forms of family violence, neighbors may be well aware of child abuse happening in the home because they hear it taking place, witness resulting child injuries, and participate in conversations with parents who openly discuss physical punishment of their child.

One can further surmise that behaviors that predict PCA, such as excessive physical punishment, may become normalized when parents observe others using it excessively, and the normalization of the behavior contributes to its spread, similar to Fagan et al.' (2007) theory related to the spread of youth homicide. Future research is needed to confirm whether factors such as social norms are a mechanism contributing to spatial spread of PCA. Furthermore, studies examining social networks could further illuminate potential social norms mechanisms (see Bond \& Bushman, 2017). In the current study, we were unable to test whether social norms or social networks are a mechanism that explains the spread in PCA over time because social network data were not available. Replication and testing the mechanisms that underlie spatial spread of PCA over time is an important direction for future research.

\subsection{Policy and practice implications}

Child welfare and police agencies could use administrative data to identify neighborhoods with disproportionately high rates of physical child abuse and work with social services to focus intervention efforts in those communities. Although, as noted previously, the current study does not identify a specific mechanism that may contribute to the "spread" of physical child abuse observed in the current study, social norms are a plausible explanation. To that end, the Centers for Disease Control and Prevention suggests several prevention strategies that relate to shifting social norms at multiple levels, including public health and education campaigns, and further suggests that "Legislative approaches to reduce corporal punishment can help establish norms around safe, more effective discipline strategies to reduce the harms of harsh physical punishment, particularly if paired with engagement and education campaigns" (Fortson, Klevens, Merrick, Gilbert, \& Alexander, 2016).

Increasing the availability of evidence-based parenting resources with demonstrated effectiveness in reducing PCA practices in neighborhoods with fewer children relative to the number of adults may yield improvements. As Christakis and Fowler (2007) discussed in relation to their research on the social contagion of smoking, if a harmful behavior is contagious, so too is quitting that behavior. Intervention programs can take advantage of this approach. "The wonderful property of social networks is that they augment what you seed them with, so if you can seed a network with a smoking cessation program [or, we would suggest, a child abuse prevention program], you will get multiplicative power in getting results" (Park, 2008). Also, our findings suggest that continued prevention efforts focusing on improving socio-economic conditions in impoverished neighborhoods may yield real benefits in children's well-being, specifically with respect to reducing their risk of experiencing PCA severe enough to warrant police involvement.

\subsection{Direction for future research}

The results of this study indicate that citywide analyses using this kind of administrative data may be fruitful for understanding the mechanisms that explain rates of child maltreatment, above and beyond parenting behaviors per se. Several approaches seem warranted. First, continuing to use spatial models for longitudinal data, or other closely related models for panel data, may provide insight into neighborhood-level factors associated with levels of child abuse that are potentially causal. Second, research would benefit from data that contains precise geo-locations of study participants that can be linked to Census data to derive information about their neighborhood characteristics or that include a rich set of covariates at both the neighborhood, individual, and family levels. Data that satisfy these requirements are not available - that we know of - in any large secondary survey data sets. However, efforts are currently underway to include rich neighborhood-level data from the U.S. Census in the next iteration of the National Survey of Child and Adolescent Well-Being (NSCAW III), a nationally representative survey of families referred to the U.S. child welfare system. Additionally, many recent efforts have used administrative data that are merged across multiple social welfare systems and could similarly be linked to neighborhood-level survey and/or Census data. Such data may provide an effective avenue for this kind of analysis.

\subsection{Limitations}

First, the data accessed from the police department, which provided these publicly available data are anonymized. As a result, it was not possible to ascertain whether the same individual or family is represented across multiple cases. While the data likely represent the most severe cases of PCA (Cross et al., 2005), there is no measure of the severity of the incident. Another potential limitation is that Census tracts may not be an accurate operational definition for neighborhood units and smaller boundaries such as Census block groups, may better capture resident perceptions of neighborhood context. However, due to the infrequent cases of police-investigated PCA, data at the Census block level did not capture neighborhood-level variations in the outcome. We also note that while administrative units have limitations, extant research considers Census tracts as a reasonable proxy of physical attributes and residents' perceived neighborhood boundaries (Ernst, 2001; Klein \& Merritt, 2014).

Furthermore, the police data were not linked to other information (e.g., CPS data) about the children and families under investigation; thus we are not able to control for individual- or family-level characteristics that might also influence the risk of policeinvestigations for PCA. As a result, our analysis is unable to ascertain the degree to which individual- and family-level characteristics may mediate or moderate the results described herein. Additionally, the current study cannot determine the mechanisms that may 
explain the spatial spread; for example, we are unable to investigate social norms (Fagan et al., 2007), collective efficacy (Sampson et al., 1997), or other factors that may contribute to the spread of police-investigated PCA over time. Rather, we are only able to say that neighborhood diffusion processes appear to explain some of the variations in the rates of police-investigated PCA. Lastly, our measure captures a particular form of PCA, that is, PCA that comes to the attention of police. Therefore, it is an indirect measure of actual parent-to-child physical abuse. An important direction for future research would be to relate police-investigated PCA to other data, such as CPS reports. Such analyses would be well suited to examine whether there exist similar contagion processes for CPSinvestigated and police-investigated PCA, and may provide additional information on individuals and families that could allow for analyses to examine the individual-level or family-level characteristics in spatial contagion processes.

\section{Conclusion}

This study finds that police-investigated physical child abuse is more common in neighborhoods that are in close proximal spatial contexts with other neighborhoods that have high rates of child abuse. Every additional case of PCA in neighboring Census tracts was found to be associated with .46 more abuse cases in the focal tract. This provides preliminary evidence that PCA, like other problematic behaviors, may "spread" across neighborhoods over time. Our findings support the utility of mapping child abuse incidents to help social services and law enforcement agencies predict the locations of future incidents (e.g., "smart policing" or social service delivery). This is the first study of which we are aware of using a spatial lag model to measure maltreatment at the neighborhood level for the explicit purpose of examining whether maltreatment spreads across neighborhoods over time. Additionally, to our knowledge, it is only the third study of any kind to use the longitudinal measurement of neighborhood effects on child maltreatment.

\section{References}

Almgren, G. (2005). The ecological context of interpersonal violence: From culture to collective efficacy. Journal of Interpersonal Violence, 20(2), 218-224. https://doi. org $/ 10.1177 / 0886260504267741$.

Andresen, M. A. (2006). A spatial analysis of crime in Vancouver, British Columbia: A synthesis of social disorganization and routine activity theory. The Canadian Geographer/Le Géographe canadien, 50(4), 487-502. https://doi.org/10.1111/j.1541-0064.2006.00159.x.

Andresen, M. A., \& Jenion, G. W. (2008). Crime prevention and the science of where people are. Criminal Justice Policy Review, 19(2), 164-180. https://doi.org/10. $1177 / 0887403407311591$.

Belsky, J. (1993). Etiology of child maltreatment: A developmental-ecological analysis. Psychological Bulletin, 114(3), 413-434. https://doi.org/10.1037/0033-2909. 114.3.413.

Bingenheimer, J. B., Brennan, R. T., \& Earls, F. J. (2005). Firearm violence exposure and serious violent behavior. Science, 308(5726), 1323-1326. https://doi.org/10. 1126/science.1110096.

Bond, R. M., \& Bushman, B. (2017). The contagious spread of violence among adolescents through social networks. American Journal of Public Health, 107(2), 288-294. https://doi.org/10.2105/A.JPH.2016.

Caplan, J. M., Marotta, P., Piza, E. L., \& Kennedy, L. W. (2014). Spatial risk factors of felonious battery to police officers. Policing: An International Journal of Police Strategies \& Management, 37(4), 823-838. https://doi.org/10.1108/PIJPSM-04-2014-0045.

Christakis, N. A., \& Fowler, J. H. (2007). The spread of obesity in a large social network over 32 years. The New England Journal of Medicine, 357(4), 370-379. https:// doi.org/10.1056/NEJMsa066082.

Corso, P. S., Edwards, V. J., Fang, X., \& Mercy, J. A. (2008). Health-related quality of life among adults who experienced maltreatment during childhood. American Journal of Public Health, 98(6), 1094-1100. https://doi.org/10.2105/AJPH.2007.119826.

Coulton, C. J., Crampton, D. S., Irwin, M., Spilsbury, J. C., \& Korbin, J. E. (2007). How neighborhoods influence child maltreatment: A review of the literature and alternative pathways. Child Abuse \& Neglect, 31(11-12), 1117-1142. https://doi.org/10.1016/j.chiabu.2007.03.023.

Coulton, C. J., Jennings, M. Z., \& Chan, T. (2013). How big is my neighborhood? Individual and contextual effects on perceptions of neighborhood scale. American Journal of Community Psychology, 51(1-2), 140-150. https://doi.org/10.1007/s10464-012-9550-6.

Coulton, C. J., Korbin, J. E., \& Su, M. (1999). Neighborhoods and child maltreatment: A multi-level study. Child Abuse \& Neglect, 23(11), 1019-1040. https://doi.org/ 10.1016/s0145-2134(99)00076-9.

Coulton, C. J., Korbin, J. E., Su, M., \& Chow, J. (1995). Community level factors and child maltreatment rates. Child Development, 66(5), 1262-1276. https://doi.org/ 10.2307/1131646.

Cross, T. P., Finkelhor, D., \& Ormrod, R. (2005). Police involvement in child protective services investigations: Literature review and secondary data analysis. Child Maltreatment, 10(3), 224-244. https://doi.org/10.1177/1077559505274506.

Cunradi, C. B., Mair, C., Ponicki, W., \& Remer, L. (2011). Alcohol outlets, neighborhood characteristics, and intimate partner violence: Ecological analysis of a California city. Journal of Urban Health, 88(2), 191-200. https://doi.org/10.1007/s11524-011-9549-6.

Degarmo, M. (2011). Understanding the comparisons of routine activities and contagious distributions of victimization: Forming a mixed model of confluence and transmission. International Journal of Criminology and Sociological Theory, 4(1), 584-603.

Drake, B., \& Pandey, S. (1996). Understanding the relationship between neighborhood poverty and specific types of child maltreatment. Child Abuse \& Neglect, 20(11), 1003-1018. https://doi.org/10.1016/0145-2134(96)00091-9.

Ernst, J. S. (2001). Community-level factors and child maltreatment in a suburban county. Social Work Research, 25(3), 133-142. https://doi.org/10.1093/swr/25.3. 133.

Emery, C. R., Trung, H. N., \& Wu, S. (2015). Neighborhood informal social control and child maltreatment: A comparison of protective and punitive approaches. Child Abuse \& Neglect, 41(2015), 158-169. https://doi.org/10.1016/j.chiabu.2013.05.002.

Ennett, S. T., Flewelling, R. L., Lindrooth, R. C., \& Norton, E. C. (1997). School and neighborhood characteristics associated with school rates of alcohol, cigarette, and marijuana use. Journal of Health and Social Behavior, 38(1), 55-71. https://doi.org/10.2307/2955361.

Fagan, J., Wilkinson, D. L., \& Davies, G. (2007). Social contagion of violence. In D. Flannery, A. Vazsonyi, \& I. Waldman (Eds.). The Cambridge handbook of violent behavior and aggression (pp. 688-723). Cambridge, UK: Cambridge University Press.

Fortson, B. L., Klevens, J., Merrick, M. T., Gilbert, L. K., \& Alexander, S. P. (2016). Preventing child abuse and neglect: A technical package for policy, norm, and programmatic activities. Atlanta, GA: Centers for Disease Control and Prevention, National Center for Injury Prevention and Control.

Freisthler, B. (2004). A spatial analysis of social disorganization, alcohol access, and rates of child maltreatment in neighborhoods. Children and Youth Services Review, 26(9), 803-819. https://doi.org/10.1016/j.childyouth.2004.02.022.

Freisthler, B. (2013). Need for an access to supportive services in the child welfare system. GeoJournal, 78(3), 429-441. https://doi.org/10.1007/s10708-011-9426-6.

Freisthler, B., Bruce, E., \& Needell, B. (2007). Understanding the geospatial relationship of neighborhood characteristics and rates of maltreatment for Black, Hispanic, and White children. Social Work, 52(1), 7-16. https://doi.org/10.1093/sw/52.1.7.

Freisthler, B., Kepple, N. J., \& Holmes, M. R. (2012). The geography of drug market activities and child maltreatment. Child Maltreatment, 17(2), 144-152. https://doi. 
org/10.1177/1077558512443124.

Freisthler, B., Lery, B., Gruenewald, P., \& Chow, J. (2006). Methods and challenges of analyzing spatial data for social work problems: The case of examining child maltreatment geographically. Social Work Research, 30(4), 198-210. https://doi.org/10.1093/swr/30.4.198.

Freisthler, B., Midinak, L. T., \& Gruenewald, P. J. (2004). Alcohol outlets and physical abuse and neglect: Applying routine activities theory to the study of child maltreatment. Journal of Studies on Alcohol, 65(5), 586-592. https://doi.org/10.15288/jsa.2004.65.586.

Gorman, D. M., Zhu, L., \& Horel, S. (2005). Drug 'hot-spots', alcohol availability and violence. Drug and Alcohol Review, 24(6), 507-513. https://doi.org/10.1080/ 09595230500292946.

Gruenewald, P. J., Ponicki, W. R., Remer, L. G., Waller, L. A., Zhu, L., \& Gorman, D. M. (2013). Mapping the spread of methamphetamine abuse in California from 1995 to 2008. American Journal of Public Health, 103(7), 1262-1270. https://doi.org/10.2105/AJPH.2012.300779.

Klein, S. (2011). The availability of neighborhood early care and education resources and the maltreatment of young children. Child Maltreatment, 16(4), 300-311 https://doi.org/10.1177\%2F1077559511428801.

Klein, S., \& Merritt, D. H. (2014). Neighborhood racial and ethnic diversity as a predictor of child welfare system involvement. Children and Youth Services Review, 41(2014), 95-105.

Lery, B. (2009). Neighborhood structure and foster care entry risk: The role of spatial scale in defining neighborhoods. Children and Youth Services Review, 31, 331-337. https://doi.org/10.1016/j.childyouth.2008.08.001.

Lai, P. C., \& So, F. M. (2009). Spatial epidemiological approaches in disease mapping and analysis. Boca Raton, FL: CRC Press.

Merritt, D. H. (2009). Child abuse potential: Correlates with child maltreatment rates and structural measures of neighborhoods. Children and Youth Services Review, 31(8), 927-934. https://doi.org/10.1016/j.childyouth.2009.04.009.

Molnar, B. E., Buka, S. L., Brennan, R. T., Holton, J. K., \& Earls, F. (2003). A multilevel study of neighborhoods and parent-to-child physical aggression: Results from the Project on Human Development in Chicago neighborhoods. Child Maltreatment, 8(2), 84-97. https://doi.org/10.1177/1077559502250822.

Morris, M. C., Marco, M., Maguire-Jack, K., Kouros, C. D., Bailey, B., Ruiz, E., et al. (2018). Connecting child maltreatment risk with crime and neighborhood disadvantage across time and place: A Bayesian spatiotemporal analysis. Child Maltreatment, 24(2), 181-192. https://doi.org/10.1177/1077559518814364.

Park, A. (2008). Quitting smoking is contagious. Retrieved fromTimehttp://content.time.com/time/health/article/0,8599,1808446,00.html.

Paulsen, D. J. (2004). No safe place: Assessing spatial patterns of child maltreatment victimization. Journal of Aggression, Maltreatment \& Trauma, 8(1-2), 63-85. https://doi.org/10.1300/J146v08n01 03.

Rowe, D. C., Chassin, L., Presson, C. C., Edwards, D., \& Sherman, S. J. (1992). An "epidemic" model of adolescent cigarette smoking. Journal of Applied Social Psychology, 22(4), 261-285. https://doi.org/10.1111/j.1559-1816.1992.tb01539.x.

Sampson, R. J., Morenoff, J. D., \& Gannon-Rowley, T. (2002). Assessing "neighborhood effects": Social processes and new directions in research. Annual Review of Sociology, 28(2002), 443-478. https://doi.org/10.1146/annurev.soc.28.110601.141114.

Sampson, R. J., Raudenbush, S. W., \& Earls, F. (1997). Neighborhoods and violent crime: A multi-level study of collective efficacy. Science, 277(5328), 918-924. https://doi.org/10.1126/science.277.5328.918.

StataCorp (2017a). Stata spatial autoregressive models reference manual: Release 15. College Station, TX: Stata Press.

StataCorp (2017b). Stata statistical software: Release 15. College Station, TX.

United Nation's Children's Fund [UNICEF] (2003). A league table of child maltreatment deaths in rich nations. Innocenti Report Card No.5Retrieved from. Florence, Italy: UNICEF Innocenti Research Centre. www.unicef-irc.org/publications/pdf/repcard5e.pdf.

U.S. Department of Health and Human Services (2017). National child abuse and neglect data system (NCANDS) child file, FFY 2000-2014. Accessed fromAdministration for Children and Families, Administration on Children, Youth and Families, Children's Bureauhttp://datacenter.kidscount.org/data/tables/6222-children-whoare-confirmed-by-child-protective-services-as-victims-of-maltreatment-by-maltreatment-type?loc $=15 \& l o c t=2 \#$ detailed $/ 2 / 15 /$ false $/ 869,36,868,867,133 / 3885$, 3886,3887,3888,3889,3890,872/12951,12950.

Whitfield, C. L., Anda, R. F., Dube, S., \& Felitti, V. J. (2003). Violent childhood experiences and the risk of intimate partner violence in adults: Assessment in a large health maintenance organization. Journal of Interpersonal Violence, 18(2003), 166-185 https://doi.org/10.1177\%2F0886260502238733.

Wildeman, C., Emanuel, N., Leventhal, J. M., Putnam-Hornstein, E., Waldfogel, J., \& Lee, H. (2014). The prevalence of confirmed maltreatment among U.S. children, 2004 to 2011. JAMA Pediatrics, 168(8), 706-713. https://doi.org/10.1001/jamapediatrics.2014.410.

Williamson, D. F., Thompson, T. J., Anda, R. F., Dietz, W. H., \& Felitti, V. (2002). Body weight and obesity in adults and self-reported abuse in childhood. International Journal of Obesity, 26(8), 1075-1082. https://doi.org/10.1038/sj.ijo.0802038.

Zeoli, A. M., Grady, S., Pizarro, J. M., \& Melde, C. (2015). Modeling the movement of homicide by type to inform public health prevention efforts. American Journal of Public Health, 105(10), 2035-2041. https://doi.org/10.2105/AJPH.2015.302732. 